Monatsschrift für Geburtshülfe und Gynäkologie 1905;22:406

\title{
Ergänzende Bemerkung
}

Die Verhandlungen des Hebammenkongresses, welche im Augustheft publiziert sind, sind von Herrn Dr. Adolf Bennecke in Rostock berichtet worden. 